\title{
Evaluation of Structure, Heterogeneities, Thickness and Corrosion Protection of Electrodeposited Sol-Gel Superhydrophobic Coatings
}

\author{
Gabriel B. Leoni ${ }^{a *}$ (D), Denise S. de Freitas ${ }^{a}$,José A. P. da C. Gomes ${ }^{b}$ (D), Simone L. D. C. Brasil \\ ${ }^{a}$ Instituto Nacional de Tecnologia, Divisão de corrosão, Rio de Janeiro, RJ, Brasil. \\ ${ }^{b}$ Universidade Federal do Rio de Janeiro, Instituto Alberto Luiz Coimbra de Pós-Graduação e Pesquisa \\ de Engenharia, Rio de Janeiro, RJ, Brasil. \\ 'Universidade Federal do Rio de Janeiro, Escola de Química, Rio de Janeiro, RJ, Brasil.
}

Received: September 12, 2021; Revised: December 16, 2021; Accepted: December 18, 2021

\begin{abstract}
The present work evaluated the structure and heterogeneities, surface chemistry, hydrophobicity level, and corrosion protection in a saline environment of electrodeposited sol-gel superhydrophobic coatings on carbon steel, using microscopy techniques, energy dispersive X-ray spectroscopy (EDX), water contact angle measurements, and electrochemical impedance spectroscopy (EIS). Furthermore, the effect of silane precursor concentration on the aforementioned response variables was tested. Regarding the structure, results point out rough deposits composed of two layers with different properties and thicknesses, and preferential deposition on the top area of the carbon steel coupon. Elemental mapping proved the chemical stability of the film in $\mathrm{NaCl} 3.5 \%$ wt., while increasing the amounts of silane precursor up to $40 \mathrm{mmol}$ showed also increased results for water contact angle $\left(157^{\circ}\right)$, impedance modulus at $0.01 \mathrm{~Hz}\left(10^{7} \mathrm{Ohm} . \mathrm{cm}^{2}\right)$, and film thickness $(70 \mu \mathrm{m})$. However, the addition of greater amounts resulted in miscibility issues in the hydrolysis solution.
\end{abstract}

Keywords: Sol-Gel, electrodeposition, superhydrophobicity, heterogeneities, corrosion.

\section{Introduction}

Superhydrophobic surfaces present the ability to repel polar liquids such as water so that the angle formed between the solid surface and the tangent of a water droplet is superior to $150^{\circ}{ }^{1}$. Such lack of affinity with water provides materials with important properties such as self-cleaning ${ }^{2,3}$, anti-fogging ${ }^{4,5}$, low friction in water ${ }^{6,7}$, and coatings with improved barrier against water permeation, and, consequently, corrosion protection ${ }^{8-10}$. Among the available methods to fabricate such surfaces, one not yet very well explored is the electrodeposition of sol-gel superhydrophobic coatings using silane precursors.

Although not explicitly designed to fabricate superhydrophobic surfaces, the electrodeposition of sol-gel coatings was first reported by Shacham et al. ${ }^{11}$, resorting to the electrochemical generation of hydroxyl ions on conductive materials in order to control siloxane condensation reaction rates, sol stability, and, consequently, film deposition. The technique's high controllability and the diversity of silane precursor commercially available allowed the fabrication of surfaces embodying micro and nanoscale roughness (hierarchical structures) and low surface energy, conditions required to produce superhydrophobic surfaces. Wu et al. ${ }^{12}$ developed electrodeposited coatings combining tetraethoxysilane (TEOS) and dodecyltrimethoxysilane (DTMS), a precursor with a long alkyl chain and responsible for the surface energy

*e-mail: gabrielbleoni@ufrj.br reduction, under $-1.3 \mathrm{~V}$ during 300 seconds. The produced superhydrophobic coating presented water contact angles (WCA) close to $155^{\circ}$, thickness of $3 \mu \mathrm{m}$, and impedance modulus of the order of $10^{5} \mathrm{Ohm} . \mathrm{cm}^{2}$ after 48 hours of immersion in $\mathrm{NaCl} 3.5 \%$ wt.

Other authors ${ }^{13,14}$, on the other hand, proposed the fabrication of the superhydrophobic surface by electrodeposition of TEOS followed by immersion in a sol embodying hydrolysed (DTMS). Their methodology yielded thicker coatings $(\sim 20 \mu \mathrm{m})$, but similar WCA to the work from Wu et al. ${ }^{12}$. In a previous work published by our research group ${ }^{15}, 11$ variables associated with sol-gel processing, electrodeposition, and film drying were evaluated to maximize WCA and impedance modulus in $\mathrm{NaCl} 3.5 \%$ wt. of superhydrophobic coatings produced by the combination of TEOS and octyltriethoxysilane (OTES). Films produced under improved conditions obtained WCA superior to $157^{\circ}$, thicknesses close to $70 \mu \mathrm{m}$, and impedance modulus superior to $10^{6} \mathrm{Ohm} . \mathrm{cm}^{2}$ even after 48 hours of immersion in $\mathrm{NaCl} 3.5 \%$ wt.

This work complemented previously published results ${ }^{15}$, following its methodology for film formation, and analysed in detail the structure of the film and its heterogeneities, as well as their influence on the corrosion behaviour of carbon steel. Furthermore, the effect of the amount of TEOS and OTES added to the system while maintaining their molar ratio equal to 1 , was evaluated considering the WCA, film thickness, corrosion protection, and film heterogeneities as response variables. 


\section{Methodology}

Carbon steel SAE 1020 (C 0.190\%; Mn 0.500\%; Si $0.150 \%$; P $0.023 \%$; S $0.014 \%$ ) coupons with dimensions of $2.0 \mathrm{~cm} \times 1.5 \mathrm{~cm} \times 0.6 \mathrm{~cm}$ were used to electrodeposit the sol-gel superhydrophobic coatings. The metallic sample faces were occluded with electrical tape, leaving the face with $2.0 \mathrm{~cm} \times 1.5 \mathrm{~cm}$ exposed, which was then abraded with consecutive emery papers until 2000 grit and polished with diamond paste $(3 \mu \mathrm{m})$. Afterward, samples were rinsed with distilled water, degreased in ethanol ultrasonic bath for 5 minutes, and blow-dried with atmospheric air.

The deposition solution was composed of $30 \mathrm{~mL}$ of $\mathrm{NaNO}_{3} 0.3$ mol.L $\mathrm{L}^{-1}, 70 \mathrm{~mL}$ of ethanol $95 \%$, and different amounts of tetraethoxysilane (TEOS) 98\% and octyltriethoxysilane (OTES) 97\%, maintaining their molar ratio equal to 1 . Solution $\mathrm{pH}$ was adjusted by dropwise addition of $\mathrm{HNO}_{3} 0.1 \mathrm{~mol} . \mathrm{L}^{-1}$, and hydrolysis proceeded for 5 hours under stirring $(550 \mathrm{rpm})$. It is important to point out that $\mathrm{NaNO}_{3}$ was employed in order to control the sol stability and conductivity, which, among other variables, are important factors for electrodeposition, as described in a previous work ${ }^{15}$.

At the end of the hydrolysis, a calomel $\left(3.0 \mathrm{~mol} . \mathrm{L}^{-1}\right)$ reference electrode, a titanium sheet $(3.0 \mathrm{~cm} \mathrm{x} 3.8 \mathrm{~cm})$ as counter electrode, and the aforementioned carbon steel coupon as working electrode, were immersed in an electrochemical cell containing the deposition solution, as shown in Figure 1a and b. Since the reference electrode used in the present work was calomel 3.0 mol. $\mathrm{L}^{-1}$, all potentials mentioned herein refer to such electrode.
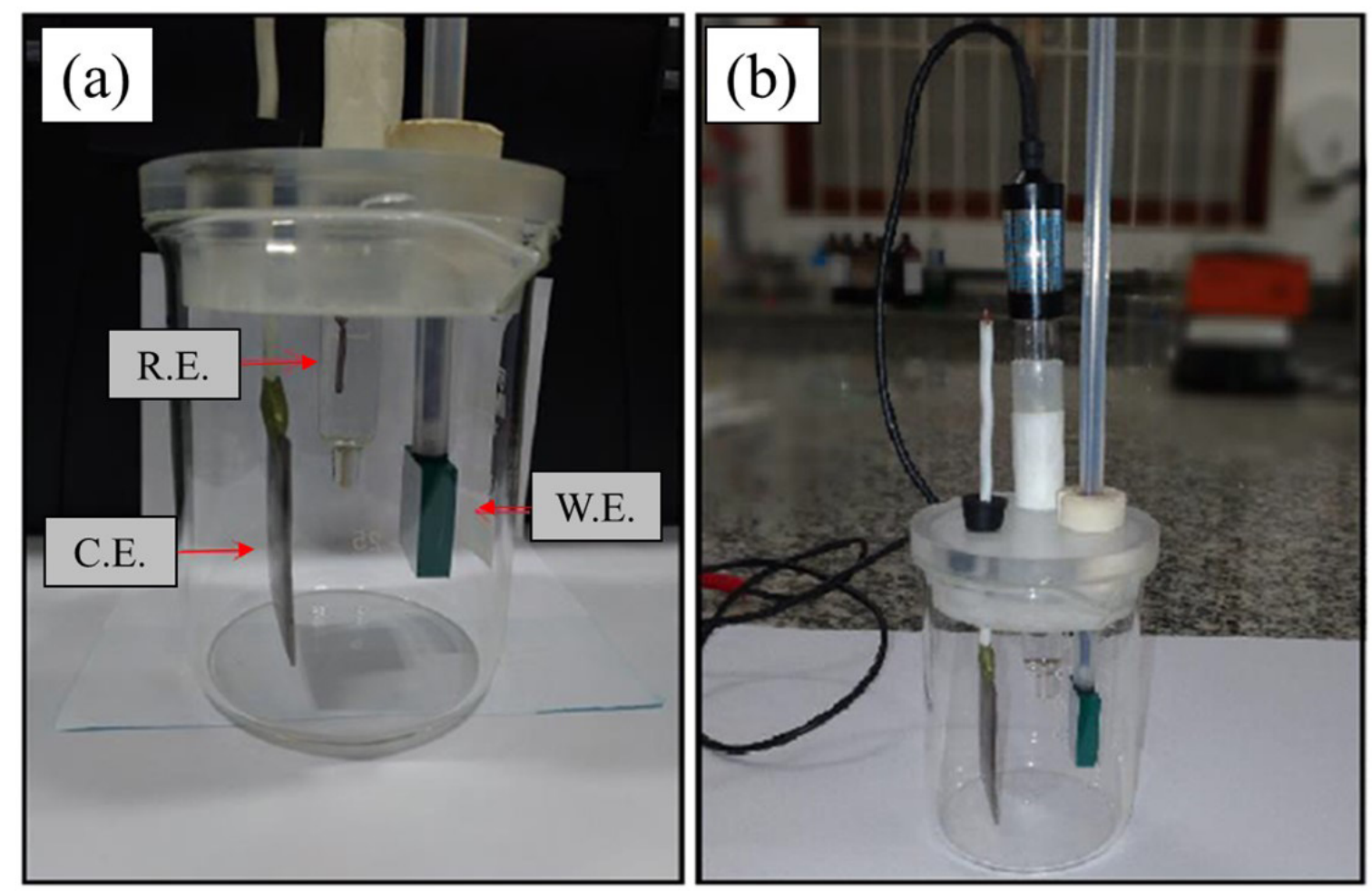

Electrodeposition took place in a Faraday cage under the potential of $-1.3 \mathrm{~V}$, which was controlled by the potentiostat PSGTAT302N (Metrohm), for 780 seconds. Once deposits were formed, coupons were rinsed with distilled water and ethanol and dried for 3 hours under $120^{\circ} \mathrm{C}$ in a lab oven (SPlabor).

Static water contact angle measurements were performed using the goniometer from Ossila, positioning five droplets with $8.0 \mu \mathrm{L}$ each on different coating regions. Surface morphology was analysed by optical microscopy (Smartzoom 5, ZEISS) and scanning electron microscopy (SEM, VEGA 3, TESCAN), while surface elemental mapping was obtained by energy-dispersive X-ray spectroscopy (EDS, QUANTAX EDS, Bruker).

Film thicknesses were measured by partially occluding with electrical tape, prior to deposition, the $2.0 \mathrm{~cm} \times 1.5 \mathrm{~cm}$ carbon steel face, leaving only a $1 \mathrm{~cm}^{2}$ area with squared shape unmasked. After deposition, the tape was removed, exposing a height difference between the coating and the carbon steel. Such height was measured through the 3D profile tool from Smartzoom 5 (ZEISS) on the coating regions marked by the letters from $A$ to $L$ in Figure 2 .

Electrochemical impedance spectroscopy analyses were performed using the aforementioned three-electrode cell, exposing an area of $0.64 \mathrm{~cm}^{2}$ to $\mathrm{NaCl} 3.5 \%$ wt. Once again, measurements were conducted inside a Faraday cage and controlled by the potentiostat PSGTAT302N. The sinusoidal amplitude was $10 \mathrm{mV}$, and frequencies varied from $10^{5} \mathrm{~Hz}$ to $10^{-2} \mathrm{~Hz}$, performing eight measures per frequency decade.

Figure 1. (a) Example of electrodeposition cell presenting the positioning of the working electrode (W.E.), counter electrode (C.E.), and reference electrode (R.E.) and (b) overall cell view. 


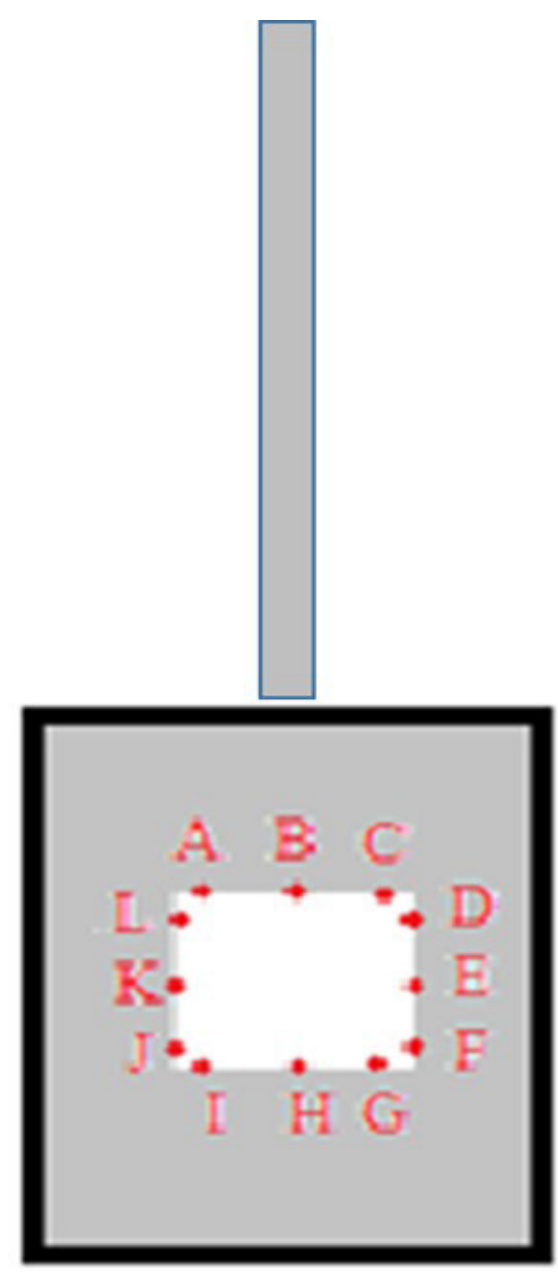

Figure 2. Scheme of the coated region (white) used for film thickness measurements and the regions where such measurements were taken marked by the letters $A$ to $L$.

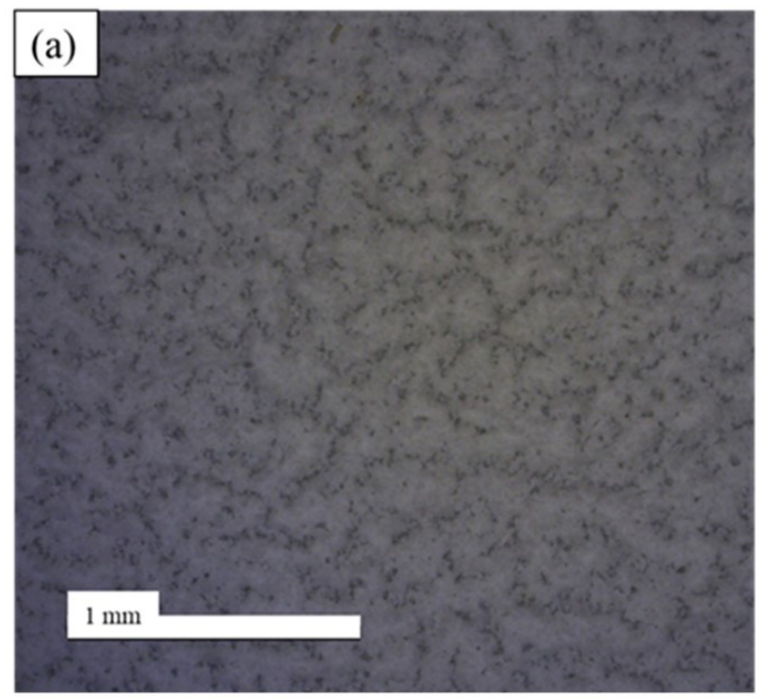

\section{Results And Discussion}

Results of the analysis of coating morphology are shown in Figure 3. As it can be seen, it presents high porosity and roughness in millimetric and micrometric scales, which can indeed entrap air, increasing surface hydrophobicity. It is worth noting that, even though the applied techniques cannot detect nanometric scales, its presence is also expected due to the water contact angle values superior to $157^{\circ}$ obtained by such film in previous work ${ }^{15}$, in agreement with the CassieBaxter model ${ }^{16}$. Furthermore, the analysis of Figure 3 points out that the deposit formation was given by the random agglomeration of particles slightly smaller than $5 \mu \mathrm{m}$.

Further on, a double-layer structure on deposit could also be noticed, i.e., the coating was formed by a thin inner layer and well adhered to the metal, and a thick outer layer, presenting higher porosity and low cohesion, deposited above the first layer. Figure $4 \mathrm{a}$ presents the outer and inner layer optical microscopy of the deposits. The former was exposed after successive contacts between the coating and an adhesive tape, where no pressure was applied upon. Each time, the tapes were removed by pulling one of its sides with an angle of approximately $45^{\circ}$. As long as the structure of the outer layer was present, it offered no resistance during the pulling process. The inner layer, on the other hand, remained intact despite several cycles, proving its higher cohesive capability.

Figure $4 \mathrm{~b}$ describes the height difference between both layers caused by the contact with the adhesive tape. Sibottier et al. ${ }^{17}$ described a similar structure with different densities deposited above gold electrodes and studied their formation using a quartz crystal microbalance. Based on their conclusions, it was possible to propose a similar theory regarding the formation of the dual-layered structure. Due to the electrochemical generation of hydroxyl ions, which is a catalyst to condensation reactions and, consequently, to the gelation process, aggregation begins more intensely within the diffusion layer. Since the concentration of catalyst and

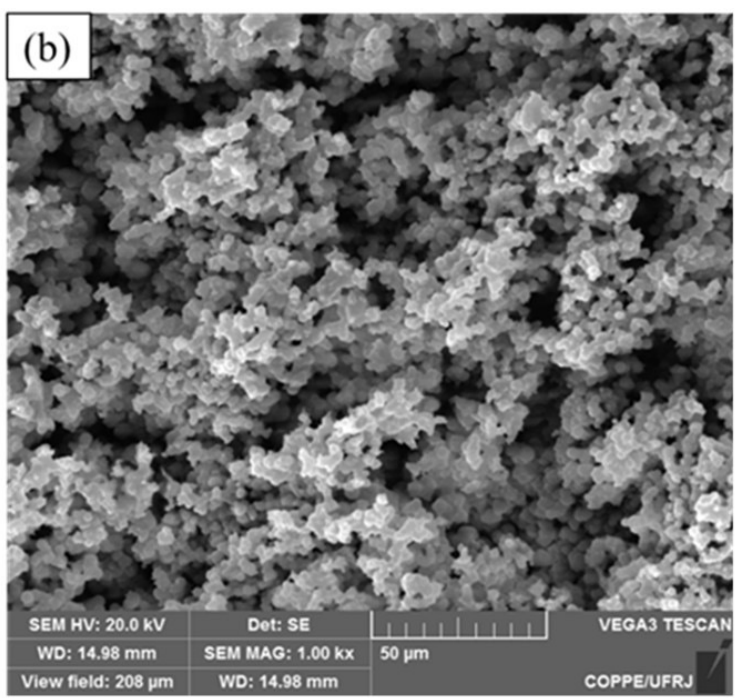

Figure 3. (a) optical microscopy and (b) SEM images of coating morphology. 


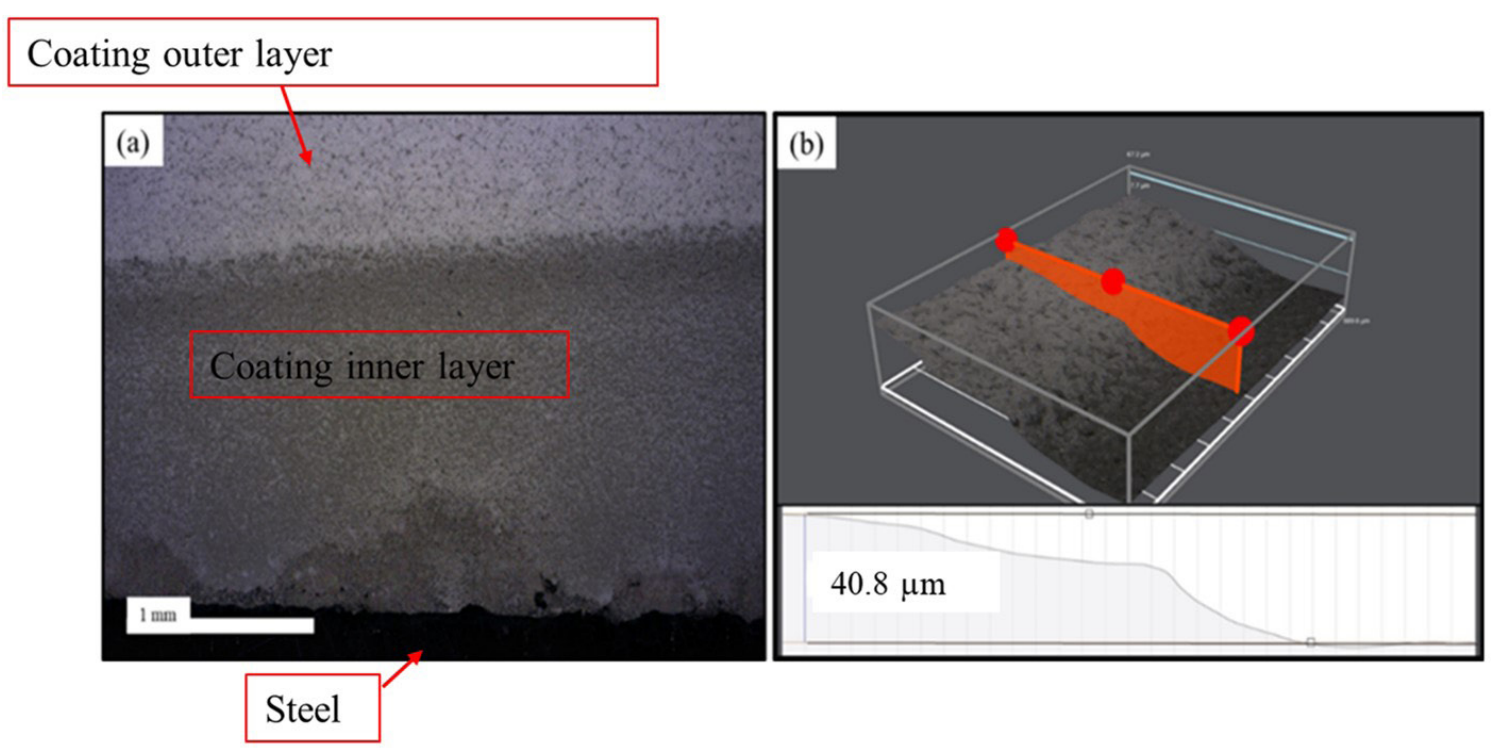

Figure 4. (a) optical microscopy identifying the double-layer structure of the deposit and (b) example of height difference between the outer and inner layers.

silanol molecules are greater in the initial period of the electrodeposition, a thin but dense layer is formed. Due to the inner layer and mass transfer resistance issues, catalyst diffusion becomes impaired, decreasing its concentration in the bulk and developing a $\mathrm{pH}$ gradient. Nevertheless, colloidal particles are still formed and increase in size with, but deposit under a less aggregate state, forming the outer layer.

The overall film thickness was $70.58 \mu \mathrm{m} \pm 18.73 \mu \mathrm{m}$, larger than other coatings deposited under similar conditions $\mathbf{s}^{12,14,18-20}$. However, one interesting fact, not yet reported, are preferential deposition regions, as shown in Table 1, which describes thickness values for the regions highlighted in Figure 2 by the letters $A$ to $L$. Based on such results, it was possible to point out that the coating top region, marked by the letter $A, B$, and $C$, provided greater thicknesses than the bottom region. It is essential to highlight that the same trend could also be identified under different deposition conditions, such as those described in our previous work ${ }^{15}$. Despite that, the methodology presented great repeatability regarding the average thickness, with standard deviation among replicates equal to $2.70 \mu \mathrm{m}$.

The literature presents possible explanations for heterogeneities in the deposits. The first one points out that larger counter electrode sizes, compared to the working electrode, such as the ones used in this work, induce the accumulation of current lines on the edges of the working electrode and, consequently, greater deposition rates ${ }^{21}$. Even though heterogeneities of this kind are prone to occur, it would not induce preferential deposition on the top region rather than the bottom one.

According to $\mathrm{Agar}^{22}$, hydrogen bubbles produced during water electrochemical reduction can induce an ascending convective movement on the surface of a vertical working electrode, explaining superior deposition on the top region. Nevertheless, for the present study, where the applied potential was $-1.3 \mathrm{~V}$, no bubbles could be identified by visual inspection.
Table 1. Film thickness measurements according to the regions described in Figure 2.

\begin{tabular}{|c|c|c|c|}
\hline Region & Location letter & $\begin{array}{l}\text { Thickness } \\
(\mu \mathrm{m})\end{array}$ & $\begin{array}{c}\text { Averaged } \\
\text { thickness } \\
(\mu \mathrm{m})\end{array}$ \\
\hline \multirow{3}{*}{ Top } & $\mathrm{A}$ & 80.00 & \\
\hline & $\mathrm{B}$ & 85.00 & 86.00 \\
\hline & $\mathrm{C}$ & 93.00 & \\
\hline \multirow{3}{*}{ Right } & $\mathrm{D}$ & 74.00 & \\
\hline & $\mathrm{E}$ & 76.00 & 68.33 \\
\hline & $\mathrm{F}$ & 55.00 & \\
\hline \multirow{3}{*}{ Bottom } & $\mathrm{G}$ & 46.00 & \\
\hline & $\mathrm{H}$ & 43.00 & 46.33 \\
\hline & I & 50.00 & \\
\hline \multirow{3}{*}{ Left } & $\mathrm{J}$ & 65.00 & \\
\hline & $\mathrm{K}$ & 80.00 & 81.67 \\
\hline & $\mathrm{L}$ & 100.00 & \\
\hline \multicolumn{2}{|c|}{ Average } & 70.58 & \\
\hline \multicolumn{2}{|c|}{ Standard Deviation } & 18.73 & \\
\hline
\end{tabular}

The third, and most plausible explanation, was given by Wagner $^{23}$ and Ibl and Müller ${ }^{24}$, which described convective ascending fluid motion caused by different densities between the diffusion layer and liquid bulk. During an electrodeposition process, if the limiting cathodic current is surpassed, reaction rates are determined by species diffusion rate, leading to its depletion within the diffusion layer, when compared to bulk. Due to gravitational effects, the less dense fluid tends to ascend, generating a natural convection motion. Such motion may be responsible for inducing more significant degrees of turbulence on the top region and altering species concentration and current distribution.

To further understand about the stability of the superhydrophobic coating on carbon steel, when immersed in $\mathrm{NaCl} 3.5 \%$ wt., and the transformations on its surface, 
SEM and EDX analysis were performed on samples before and after 48 hours of immersion. Figure 5 points out such analyses for the top, intermediate, and bottom regions of the superhydrophobic coating. Regarding the topography, it is possible to notice that the surface maintained its apparent roughness and porosity, despite the immersion. Furthermore, due to the even distribution of carbon, present in the long alkyl chains of the octyltriethoxysilane, on the elemental mapping, indicating the absence of chemical degradation. On the other hand, iron could be identified on the surface due to the presence of corrosion products, especially on the top and bottom regions. It is important to point out that most of the corrosion products mentioned above were formed on the coupon's edges, which were not properly isolated. This fact is corroborated by the lower level of iron in the intermediate region.

Table 2 presents the coating normalized elemental mass percentage before and after 48 hours of immersion. It is important to point out that, since no absolute quantification method was applied, it was not possible to draw more remarkable conclusions regarding mass variations, except by the chlorine, which was not identified before immersion, indicating the deposition of $\mathrm{NaCl}$ salt. Sodium could be identified before immersion due to the $\mathrm{NaNO}_{3}$ in the hydrolysis solution.
Furthermore, the proportion of Si:O:C before (1:1.13:1.21) and after (1:1.09:1.21) immersion remained almost constant, reassuring the absence of coating degradation.

The film tendency to protect against corrosion was first evaluated by monitoring the potential evolution through 13 hours of immersion. As shown in Figure 6a, the potential from bare steel started around $-0.50 \mathrm{~V}$ and stabilized in potentials lightly below $-0.75 \mathrm{~V}$. In contrast, the carbon steel protected with the superhydrophobic presented increasing potentials, which stabilized close to $-0.30 \mathrm{~V}$. Such difference

Table 2. Elemental mass percentage on the superhydrophobic coatings before and after 48 hours of immersion in $\mathrm{NaCl} 3.5 \% \mathrm{wt}$.

\begin{tabular}{cccccc}
\hline & \multicolumn{2}{c}{ Before immersion } & & \multicolumn{2}{c}{ After immersion } \\
\cline { 2 - 3 } \cline { 6 - 6 } Element & $\begin{array}{c}\text { Average } \\
\text { (\% wt. })\end{array}$ & $\begin{array}{c}\text { Std. } \\
\text { deviation } \\
\text { (\% wt. })\end{array}$ & & $\begin{array}{c}\text { Average } \\
(\% \text { wt. })\end{array}$ & $\begin{array}{c}\text { Std. } \\
\text { deviation } \\
\text { (\% wt. })\end{array}$ \\
\hline $\mathrm{C}$ & 20.19 & 1.91 & 21.89 & 0.92 \\
\hline $\mathrm{O}$ & 18.96 & 1.52 & & 19.81 & 0.77 \\
\hline $\mathrm{Si}$ & 16.71 & 3.04 & & 18.14 & 0.50 \\
\hline $\mathrm{Fe}$ & 1.78 & 0.91 & 1.57 & 0.33 \\
\hline $\mathrm{Na}$ & 1.11 & 0.23 & 1.97 & 0.96 \\
\hline $\mathrm{Cl}$ & 0.00 & 0.00 & 1.61 & 1.22 \\
\hline
\end{tabular}

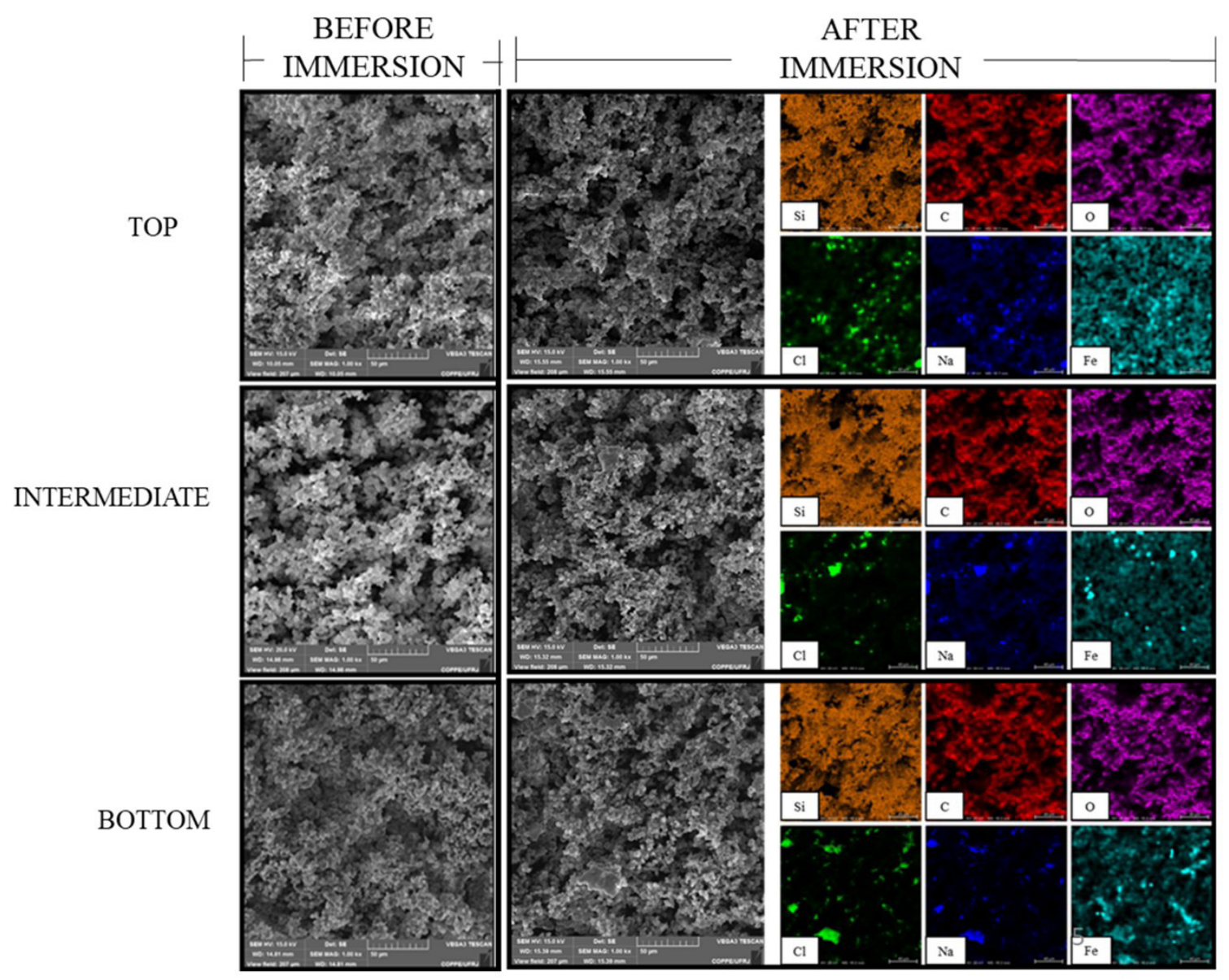

Figure 5. SEM images before and after immersion and elemental mapping of the superhydrophobic coating after immersion, considering three different regions (top, intermediate and bottom) of the sample surface. 
indicates a more noble behaviour of the coated system, and, consequently, a decreased tendency of steel to oxidize. The comparison between Figure $6 \mathrm{~b}$ and c confirm such statement, since corrosion products can clearly be seen on the surface of the bare steel, while on the coated specimen no rust was present.

The coating behaviour as a barrier against electrolyte diffusion was further investigated by electrochemical impedance spectroscopy, as shown in Figure 7, which also compares the effect of different amounts of sol-gel precursors while maintaining the molar ratio between OTES and TEOS equal to 1. Figure 7a presents the Bode plot for impedance modulus, after 5 hours of immersion in $\mathrm{NaCl} 3.5 \%$ wt., indicating that increased precursor concentrations can indeed produce more protective coatings, since the impedance modulus throughout the whole frequency range increases with precursor concentration, reaching values superior to $10^{7} \mathrm{Ohm} \cdot \mathrm{cm}^{2}$.
Complementary, Figure $7 \mathrm{~b}$ presents Bode plots for the phase angles. On higher frequencies, where capacitive behaviours strongly influence the overall measured current, greater phase angle peaks also represent a greater coating tendency to separate charges ${ }^{25}$. Based on that, it is also possible to perceive the improved barrier protection given by deposition under larger amounts of precursors, when compared to samples $10 \mathrm{mmol}$ and $25 \mathrm{mmol}$, where phase angles present initial values of $60^{\circ}$ and $20^{\circ}$, respectively, and steeply decrease with decreasing frequency. A possible explanation for the improved barrier protection given by samples $40 \mathrm{mmol}$ and $55 \mathrm{mmol}$ is associated with a thinner diffusion layer during the electrodeposition process and, consequently, the formation of thicker and denser films when higher amounts of silane are used.

It is important to point out that, on lower frequencies, the profile of the phase angle curves is inversed, displaying a more resistive behaviour for samples deposited under
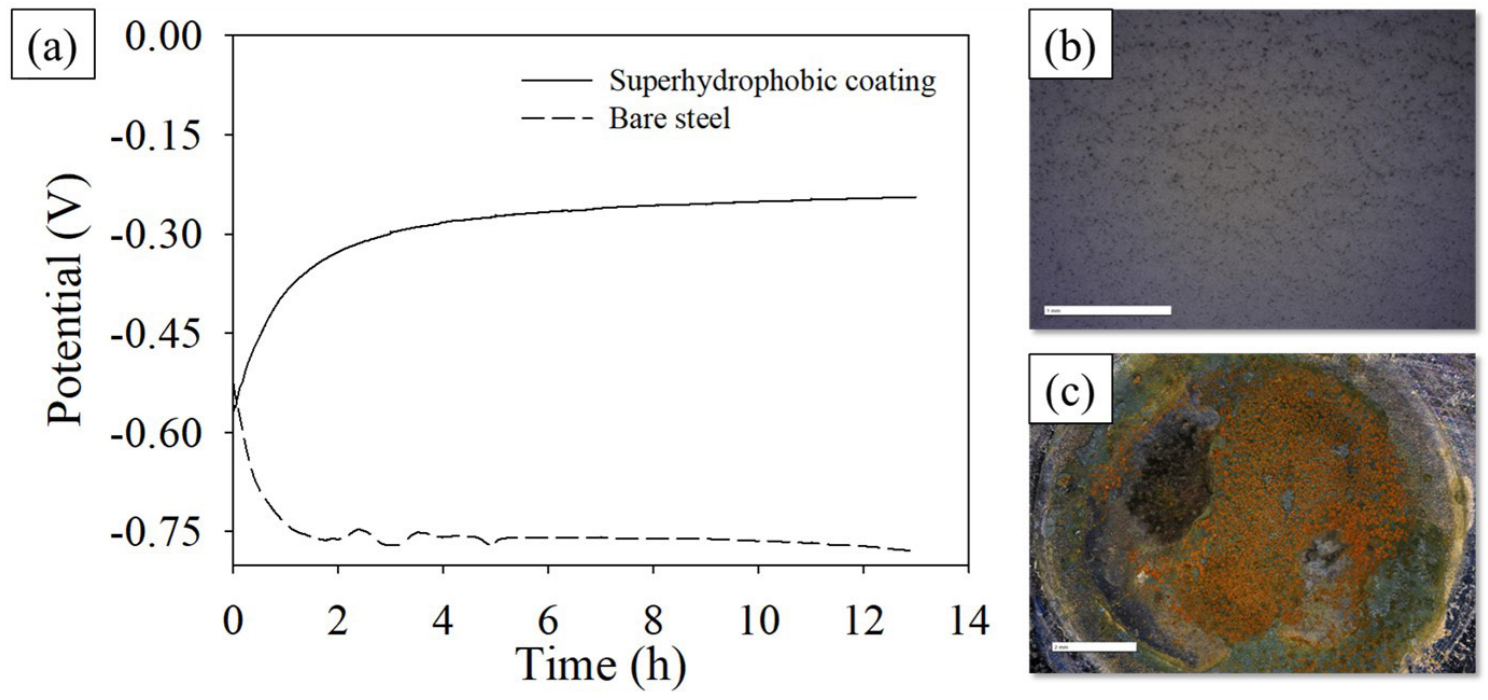

Figure 6. (a) potential monitoring throughout 13 hours of immersion in $\mathrm{NaCl} 3.5 \%$ wt. for coated and uncoated carbon steel, and optical microscopy of (b) coated and (c) uncoated carbon steel after immersion.
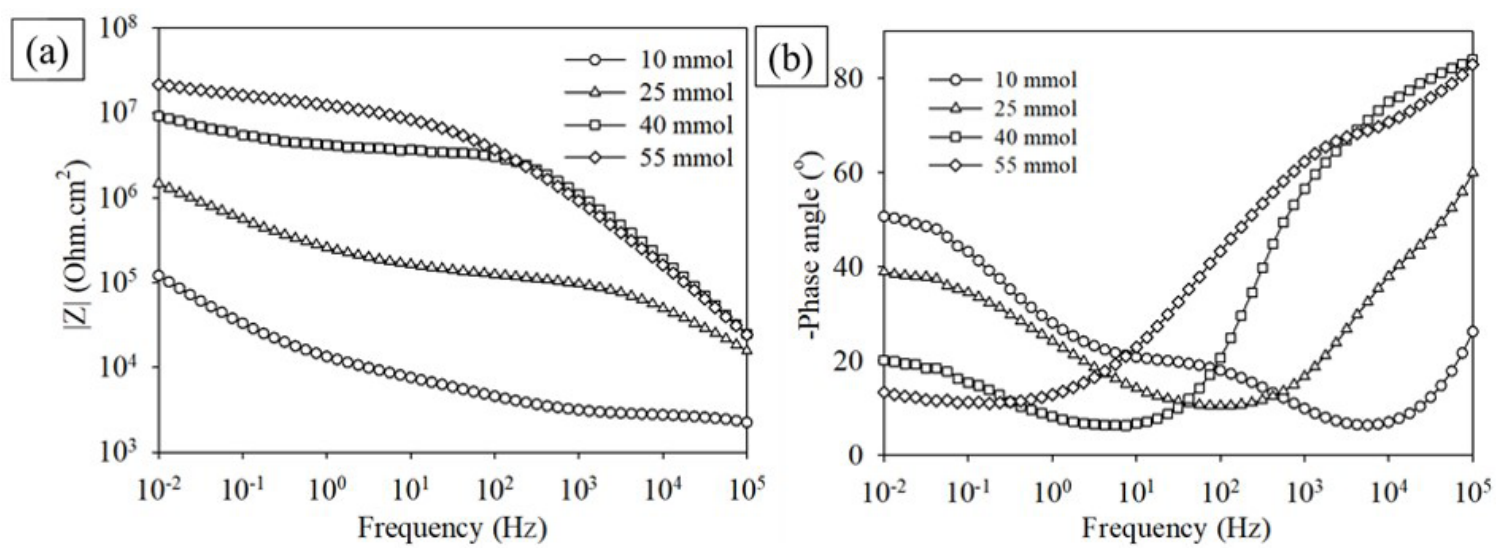

Figure 7. Bode plots for (a) impedance and (b) phase angle for superhydrophobic coatings deposited onto carbon steel considering different amounts of precursors in the hydrolysis solution, after 5 hours of immersion in $\mathrm{NaCl} 3.5 \% \mathrm{wt}$. 


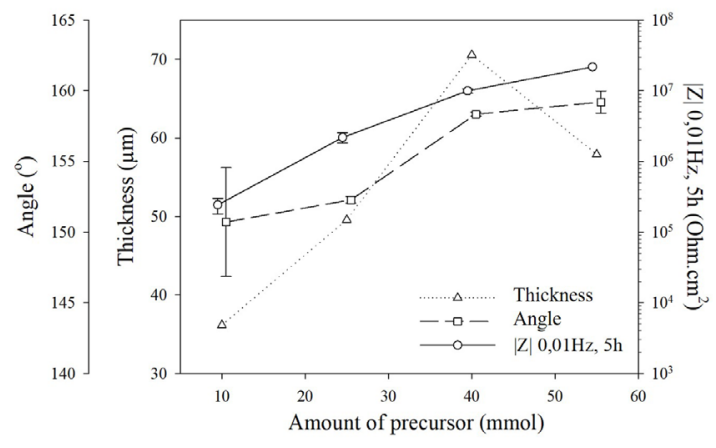

Figure 8. Response profiles as a function of the amount of silane precursor for water contact angle, film thickness, and impedance modulus at $0,01 \mathrm{~Hz}$ after 5 hours of immersion in $\mathrm{NaCl} 3.5 \% \mathrm{wt}$.

greater precursor concentrations. However, the mixed capacitive/resistive behaviours are due to mass transfer of electroactive species through the coating, indicated by the increasing profile exhibited by the impedance modulus and phased angle in low frequencies, and not necessarily to electrochemical reaction on the electrode surface. Thus, the increase of silane precursor in the electrodepositon solution provides coatings with improved barrier protection.

Figure 8 presents response profiles for water contact angle, film thickness, and impedance modulus as a function of the amount of precursors added to the hydrolysis solution, maintaining the ratio between OTES and TEOS equal to 1. The impedance profile corroborates previous results, indicating that increased precursor concentration induced greater species flux from the bulk to the metal surface during electrodeposition, yielding denser and more protective coatings. However, it also points out that such improvement is not indefinite since the curve slope slowly decreases with increasing silane amounts. A similar trend can also be identified for the water contact angle, where the angles for $40 \mathrm{mmol}$ and $55 \mathrm{mmol}$ are superior to $155^{\circ}$, but very similar, considering the error bars. The similar behaviour of water contact angle and impedance indicates that such variables are highly coupled.

Regarding the film thickness, a steep and increasing profile can be identified until $40 \mathrm{mmol}$, where the thickness was approximately $70 \mu \mathrm{m}$. However, when $55 \mathrm{mmol}$ of the precursor is added to $100 \mathrm{~mL}$ of water and ethanol solution, the average thickness decreases to $58 \mu \mathrm{m}$. Such behaviour can be explained by the partial immiscibility of the precursors in the water/ethanol mixture used in this work, resulting in small phase separation, even after the 5 hours of hydrolysis.

\section{Conclusions}

This work produced superhydrophobic films by electrodeposition of TEOS and OTES, using the sol-gel processing and evaluated its structure, heterogeneities, WCA, tendency to protect against corrosion in a saline environment, thickness, and the effect of the amount of precursors used in the hydrolysis solution. Results indicated a double-layered structure, where the inner layer was thin and cohesive, while the outer layer was much thicker ( $>$ $40 \mu \mathrm{m})$, less dense, and presented low cohesion. Preferential deposition was also identified on the top region of the coupon when compared to the bottom one, where smaller thickness values were frequently found. Possible explanations for such behaviour were discussed along the report. However, mass transfer issues causing natural convection along the vertical steel coupon seems to be the most relevant one. Nevertheless, further studies are necessary to prove such theory. Elemental mapping on film surface before and after immersion proved the chemical stability of the deposit in $\mathrm{NaCl} 3.5 \%$ wt., and the evaluation of the effect of the amount of precursor in solution indicated high water contact angles $\left(159^{\circ}\right)$ and impedance modulus $\left(2 \times 10^{7} \mathrm{Ohm}_{\mathrm{cm}}{ }^{2}\right)$ for the highest amount of precursors herein tested $(55 \mathrm{mmol})$. The film thickness, on the other hand, showed not to grow indefinitely and decreased to $58 \mu \mathrm{m}$ due to miscibility issues under $55 \mathrm{mmol}$ of precursor.

\section{References}

1. Guo Z, Liu W, Su B-L. Superhydrophobic surfaces: from natural to biomimetic to functional. J Colloid Interface Sci. 2011;353(2):335-55.

2. Zhang X-F, Zhao J-P, Hu J-M. Abrasion-resistant, hot waterrepellent and self-cleaning superhydrophobic surfaces fabricated by electrophoresis of nanoparticles in electrodeposited sol-gel films. Adv Mater Interfaces. 2017;4(2):1700177-85.

3. Latthe SS, Sutar RS, Kodag VS, Bhosale AK, Kumar AM, Kumar Sadasivuni K, et al. Self - cleaning superhydrophobic coatings: potential industrial applications. Prog Org Coat. 2019;128:52-8.

4. Lomga J, Varshney P, Nanda D, Satapathy M, Mohapatra SS, Kumar A. Fabrication of durable and regenerable superhydrophobic coatings with excellent self-cleaning and anti-fogging properties for aluminium surfaces. J Alloys Compd. 2017;702:161-70.

5. Varshney P, Lomga J, Gupta PK, Mohapatra SS, Kumar A. Durable and regenerable superhydrophobic coatings for aluminium surfaces with excellent self-cleaning and anti-fogging properties. Tribol Int. 2018;119:38-44.

6. Mertaniemi H, Jokinen V, Sainiemi L, Franssila S, Marmur A, Ikkala O, et al. Superhydrophobic tracks for low-friction, guided transport of water droplets. Adv Mater. 2011;23(26):2911-4.

7. Uemura S, Matsuo Y, Okamatsu T, Arita T, Shimomura M, Hirai Y. Low-friction, superhydrophobic, and shape-memory vulcanized rubber microspiked structures. Adv Eng Mater. 2020;22(4):1901226-31

8. Dey S, Chatterjee S, Singh BP, Bhattacharjee S, Rout TK, Sengupta DK, et al. Development of superhydrophobic corrosion resistance coating on mild steel by electrophoretic deposition. Surf Coat Tech. 2018;341:24-30.

9. Bandi P, Venkata MK, Shankar K, Beena R. Development of superhydrophobic and corrosion resistant coatings on mild steel: a greener approach. Materials Today Communications. 2020;25:101625-31.

10. Shi T, Li X, Zhang C, Wang H, He Z, Zhou X, et al. One-step preparation of the superhydrophobic Al alloy surface with enhanced corrosion and wear resistance. Materials and Corrosion. 2021;72(5):904-11

11. Shacham R, Avnir D, Mandler D. Electrodeposition of methylated sol-gel films on conducting surfaces. Adv Mater. 1999;11(5):384-8.

12. Wu LK, Zhang XF, Hu JM. Corrosion protection of mild steel by one-step electrodeposition of superhydrophobic silica film. Corros Sci. 2014;85:482-7. 
13. Wu LK, Hu J-M, Zhang J-Q, Cao C-N. Superhydrophobic surface constructed on electrodeposited sol-gel silica film. Electrochem Commun. 2013;26:85-8.

14. Zhang X, Chen R-J, Hu J-M. Superhydrophobic surface constructed on electrodeposited silica films by two-step method for corrosion protection of mild steel. Corros Sci. 2016;104:336-43.

15. Batalha Leoni G, de Freitas DS, Ponciano Gomes JAC, Brasil SLDC. Multivariable analysis of electrodeposited silane based superhydrophobic coatings for corrosion protection of carbon steel. J Sol-Gel Sci Technol. 2020;94(3):695-707.

16. Cassie ABD, Baxter S. Wettability of porous surfaces. Trans Faraday Soc. 1944;40(1):546-51.

17. Sibottier E, Sayen S, Gaboriaud F, Walcarius A. Factors affecting the preparation and properties of electrodeposited silica thin films functionalized with amine or thiol groups. Langmuir. 2006;22(20):8366-73.

18. Liu YH, Xu JB, Zhang JT, Hu JM. Electrodeposited silica film interlayer for active corrosion protection. Corros Sci. 2017;120:61-74.
19. Giordano G, Durante C, Gennaro A, Guglielmi M. Multilayer deposition of silica sol-gel films by electrochemical assisted techniques. J Phys Chem C. 2016;120(50):28820-4.

20. Chen C, Dong S, Hou R, Hu J, Jiang P, Ye C, et al. Insight into the anti-corrosion performance of electrodeposited silane/nano-CeO2 film on carbon steel. Surf Coat Tech. 2017;326:183-91.

21. Tan Y-J, Lim KY. Understanding and improving the uniformity of electrodeposition. Surf Coat Tech. 2003;167(1):255-62.

22. Agar JN. Diffusion and convection at electrodes. Discuss Faraday Soc. 1947;1(1):26-37.

23. Wagner $\mathrm{C}$. The role of natural convection in electrolytic processes. J Electrochem Soc. 1949;4(4):161-73.

24. lbl N, Müller RH. Studies of natural convection at vertical electrodes. J Electrochem Soc. 1958;105(6):346-53.

25. Fedel M, Druart M-E, Olivier M, Poelman M, Deflorian F, Rossi S. Compatibility between cataphoretic electro-coating and silane surface layer for corrosion protection of galvanized steel. Prog Org Coat. 2010;69(1):118-25. 